\title{
4-V Class Aqueous Hybrid Electrochemical Capacitor with Battery-like Capacity
}

\author{
Sho Makino, ${ }^{a}$ Yuto Shinohara, ${ }^{a}$ Takayuki Ban, ${ }^{a}$ Wataru Shimizu, ${ }^{a}$ Keita Takahashi, ${ }^{b}$ Nobuyuki \\ Imanishi, ${ }^{b}$ and Wataru Sugimoto ${ }^{* a}$
}

\author{
${ }_{5}$ Received (in $\left.X X X, X X X\right) X$ th $X X X X X X X X X 200 X$, Accepted Xth $X X X X X X X X X 200 X$ \\ DOI: 10.1039/b000000x
}

\begin{abstract}
A new aqueous hybrid electrochemical capacitor consisting of a porous positive capacitive electrode and a water-stable multi-layered $\mathrm{Li}$ negative electrode is demonstrated. The new ${ }_{10}$ cell design affords cell voltage close to $4 \mathrm{~V}$ in a mild aquous electrolytes. Application of a pseudocapacitve positive electrode with high specific charge results in specific energy comparable to present rechargeable batteries.
\end{abstract}

Electrochemical capacitors are energy storage devices 15 capable of storing/delivering electrical energy at rates faster than batteries, thereby finding application in load leveling for efficient energy usage. ${ }^{1}$ However, as the charge storage is based on reversible ion adsorption in porous electrode materials, the amount of charge that can be stored is typically limited to an 20 order smaller than batteries. Here we report a new hybrid electrochemical capacitor that can be operated using a mild aqueous electrolyte providing cell voltage as high as $4.3 \mathrm{~V}$ with specific energy of $114 \mathrm{Wh} \mathrm{kg}^{-1}$ using a $\mathrm{MnO}_{2}$ posititve electrode, or $3.8 \mathrm{~V}$ with $544 \mathrm{Wh} \mathrm{kg}^{-1}$ based on $\mathrm{RuO}_{2}$ nanosheet positive 25 electrode, potentially exceeding conventional electrochemical capacitors, hybrid electrochemical capacitors and even rechargeable batteries. The key design of the device is the appropriate choice of a pseudo-capacitive material that provides high specific capacitance and high positive potential in aqueous 30 electrolytes and a water stable multi-layered Li electrode in an asymmetric configuration. The aqueous hybrid electrochemical capacitor proposed here not only closes the gap between electrochemical capacitors and batteries, but the new design principle opens the possibility of the use of pseudo-capacitive 35 material for post lithium ion battery technology.

Electrochemical double layer capacitors (EDLC) based on a symmetric configuration of two porous carbon electrodes can deliver specific energies of up to $\sim 6 \mathrm{Wh} \mathrm{kg}^{-1}$. $^{2}$ The specific energy can be increased by using two different types of electrode 40 materials in an asymmetric configuration with one electrode behaving like an electrochemical capacitor and the other performing like a battery. ${ }^{3}$ A typical hybrid electrochemical capacitor (hybrid EC) is the lithium ion capacitor (LIC), which uses an activated carbon positive electrode and a Li-doped carbon 45 negative electrode. ${ }^{4-7}$ The charge/discharge curves of a LIC resemble that of an EDLC, and the energy and power performance of the cell is governed by the capacitive positive electrode. The cell voltage $(\sim 3.8 \mathrm{~V})$ is determined by the decomposition of the electrolyte, typically a lithium salt dissolved 50 in non-aqueous electrolytes. The low standard electrode potential of $E^{\circ}=-3.045 \mathrm{~V}$ vs $\mathrm{SHE}$ for $\mathrm{Li}^{+}+\mathrm{e}^{-} \rightarrow \mathrm{Li}$ results in a cell voltage larger than EDLCs. These characteristics lead to energy density of $\sim 15 \mathrm{Wh} \mathrm{kg}^{-1}$, which is comparable to lead-acid batteries but still cannot compete with lithium ion batteries (LiBs). 55 Thus, researchers have focused on increasing the specific capacitance of the positive electrode and developing new electrolytes. Metal oxide electrodes can provide specific capacitance higher than activated carbon owing to the contribution from highly reversible surface redox processes 60 (pseudo-capacitance). ${ }^{2,8-12}$ A typical example is ruthenium based oxides, which affords capacitance of $\sim 700 \mathrm{~F} \mathrm{~g} \mathrm{~g}^{-1}, 3$ to 7 times higher than activated carbon $\left(100-200 \mathrm{~F} \mathrm{~g} \mathrm{~g}^{-1}\right) .{ }^{13-17}$ Unfortunately, such high specific capacitance can only be achieved in aqueous electrolytes, limiting the cell voltage to $\sim 1.2 \mathrm{~V}$. Hybrid EC ${ }_{65}$ designs can circumvent the limitation of aqueous electrolytes by extending the operating voltage window beyond the thermodynamic water electrolysis voltage, giving an attractive 2 $\mathrm{V}$ device in some cases. ${ }^{3,18}$ The technology behind $2 \mathrm{~V}$ aqueous hybrid ECs is the use of a positive electrode with high oxygen 70 evolution over-potential such as manganese oxide, giving specific energy of $19 \mathrm{Wh} \mathrm{kg}^{-1} \cdot{ }^{18}$

In order to take advantage of the high specific capacitance of pseudo-capacitive oxides that can only be realized in aqueous electrolytes and at the same time utilize the low electrode 75 potential of lithium that can only be operated in non-aqueous environment, we have exploited the use of a water stable multilayered Li electrode, ${ }^{19,20}$ initially developed as the anode for an aqueous rechargeable Li-air battery. This new advanced hybrid EC can be operated using a mild aqueous electrolyte providing 80 specific energy exceeding that of LICs and potentiaally comparable to LiBs. Cell voltage as high as $4.3 \mathrm{~V}$ can be realized when $\mathrm{MnO}_{2}$ is used as the positive electrode.

The multi-layered Li electrode consists of lithium metal, a LISICON-type solid glass ceramic $\left(\mathrm{Li}_{1+x+y}(\mathrm{Ti}, \mathrm{Ge})_{2-x} \mathrm{Al}_{x} \mathrm{Si}_{y} \mathrm{P}_{3-y} \mathrm{O}_{12}\right.$ $85(x \sim 0.25, y \sim 0.3)$; Ohara Inc., Japan, hereafter denoted as LTAP) as the water-stable solid electrolyte, and a buffer layer consisting of polyethylene oxide with $\mathrm{Li}\left(\mathrm{CF}_{3} \mathrm{SO}_{2}\right)_{2} \mathrm{~N}$ polymer electrolyte (PEO-LiTFSI) between the lithium metal and the solid electrolyte. These 3 layers were sealed leaving a $5 \mathrm{~mm}$ x $5 \mathrm{~mm}$ window cut 90 out for the solid electrolyte (LTAP) to come into contact with the aqueous electrolyte. Figure 1 illustrates the cell configuration of 
the advanced hybrid EC.

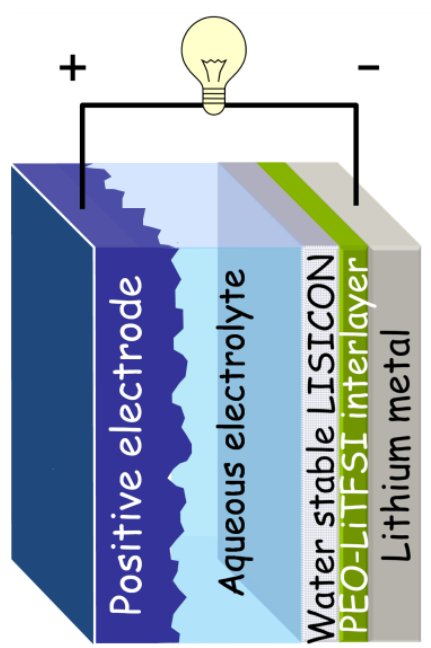

Fig. 1 Schematic representation of the aqueous hybrid EC using multilayered $\mathrm{Li}$ electrode.

Four materials were used as the positive electrode. Activated carbon (AC; 2,000 $\mathrm{m}^{2} \mathrm{~g}^{-1}$, MSP-20, Kansai Coke and Chemicals, Japan) was used as received. $\mathrm{MnO}_{2}, \mathrm{RuO}_{2} \cdot 0.5 \mathrm{H}_{2} \mathrm{O}$ and $\mathrm{RuO}_{2}$ nanosheets were prepared according to literature. ${ }^{18,21,17,22}$ The positive electrodes were prepared by depositing a controlled 10 amount of the active material dispersed in ultra-pure $\mathrm{H}_{2} \mathrm{O}$ onto a mirror-polished glassy carbon electrode (5 $\mathrm{mm}$ in diameter). The

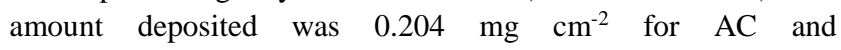
$\mathrm{MnO}_{2}+$ acetylene black (7:3 in mass), and $\mathrm{RuO}_{2} \cdot 0.5 \mathrm{H}_{2} \mathrm{O}$. In the case of $\mathrm{RuO}_{2}$ nanosheets the deposited mass was $0.0204 \mathrm{mg} \mathrm{cm}^{-2}$.

15 In order to evaluate the electrochemical capacitor properties of the positive electrodes, cyclic voltammetry was conducted in 1.0 $\mathrm{M} \mathrm{LiCl}$ or $\mathrm{Li}_{2} \mathrm{SO}_{4}\left(60^{\circ} \mathrm{C}\right)$ using a three electrode cell comprised of a $\mathrm{Ag} / \mathrm{AgCl}$ reference electrode and a platinum counter electrode. Electrode potentials will be referred to the reversible 20 hydrogen electrode (RHE) potential scale. A Luggin capillary faced the working electrode at a distance of $2 \mathrm{~mm}$. Cyclic voltammetry was conducted between 0.2 and $1.2 \mathrm{~V}$ vs RHE at scan rates of 500 to $5 \mathrm{mV} \mathrm{s}^{-1}$. The specific capacitance was calculated by averaging the anodic and cathodic charge from the 25 cyclic voltammogram.

Test cells were constructed by immersing the multi-layered Li electrode and positive electrode and in an aqueous electrolyte and can be expressed as Li | PEO-LiTFSI | LTAP | $1.0 \mathrm{M} \mathrm{LiCl}$ or $\mathrm{Li}_{2} \mathrm{SO}_{4}$ aq. | positive electrode Charge/discharge cycle tests were 30 obtained with beaker-type flooded cells at $60^{\circ} \mathrm{C}$ in a two electrode configuration. The specific charge was determined from the discharge curves based on the mass of the positive electrode unless otherwise noted. The specific capacitance in the twoelectrode system was calculated following eqation,

35

$$
C=I \cdot \mathrm{d} t / \mathrm{d} V
$$

where $I$ is discharge current normalized bt the mass of electrode material and $\mathrm{d} V / \mathrm{d} t$ is the slope of the discharge curve (excluding the voltage drop). The specific energy was calculated by integration of the area (cell voltage vs. capacity) of discharge 40 curves (shaded area in Fig. 3). The often used equation of $1 / 2$ $C\left(V_{1}{ }^{2}-V_{2}{ }^{2}\right)$ for calculation of the energy density of electrochemical capacitors, where $V_{1}$ is the higher cut-off voltage and $V_{2}$ is the lower voltage cut-off voltage, was not apllied in this work. This equation is valid only when the slope of the discharge 45 curve is completely linear and specific energy obtained from this equation will be overestimated in cases where the slope is concave.

As a proof-of-concept to demonstrate the principle operation of the advanced hybrid EC, activated carbon (AC) was first 50 chosen as the positive electrode. A neutral aqueous electrolyte (1 $\mathrm{M} \mathrm{LiCl}$ ) was used in this study to avoid unsolicited degradation of the solid electrolyte and the temperature of the cell was set at $60^{\circ} \mathrm{C}$ to ensure good conductivity of the multi-layered Li negative electrode. ${ }^{19}$ First, the EDLC behavior of the AC electrode was 55 characterized in a three-electrode configuration. The cyclic voltammogram of the AC electrode exhibits a rectangular form, typical of non-Faradaic electric double layer formation at the electrode-electrolyte interface (Fig. 2). The specific capacitance was $100 \mathrm{~F} \mathrm{~g}^{-1}$ at a scan rate of $5 \mathrm{mV} \mathrm{s}^{-1}$. Steady-state 60 charge/discharge curves of the hybrid EC (Li | PEO-LiTFSI | LTAP | $1.0 \mathrm{M} \mathrm{LiCl}$ aq. | AC) cycled between 2.9 and $3.9 \mathrm{~V}$ at a constant current density of $0.255 \mathrm{~mA} \mathrm{~cm}^{-2}$ are shown in Fig. 3(a). The voltage increases/decreases linearly with time, typical of capacitive charge storage/release. The specific charge and 65 capacitance calculated based on the $\mathrm{AC}$ electrode from the discharge curve was $32.7 \mathrm{mAh} \mathrm{g}^{-1}$ and $124 \mathrm{~F} \mathrm{~g}^{-1}$, respectively, in agreement with the capacitance obtained for the AC electrode in a three-electrode configuration. The specific energy is $108 \mathrm{Wh} \mathrm{kg}^{-1}$. Consecutive cycling tests conducted at $0.255 \mathrm{~mA} \mathrm{~cm}^{-2}$ showed 70 good capacitance retention with only 5 and $27 \%$ loss in specific capacity after 200 and 2,000 cycles, respectively. The loss in performance is dominated by the degradation of the multi-layered Li negative electrode.

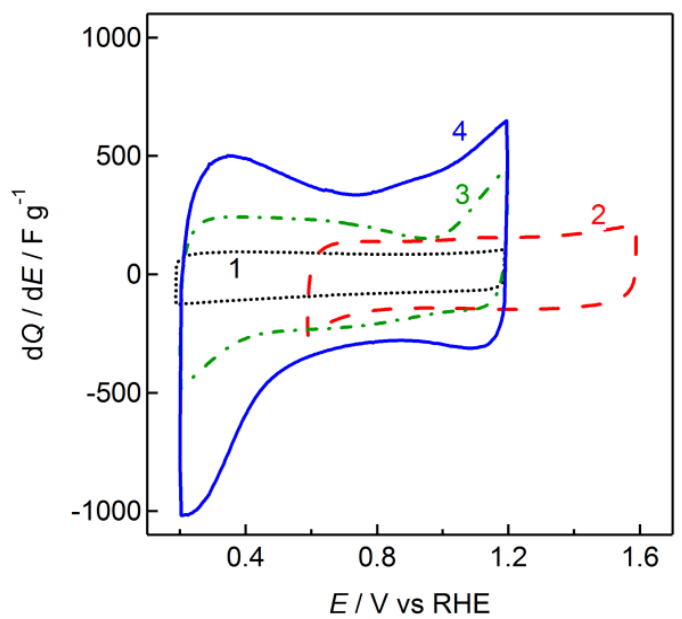

75 Fig. 2 Cyclic voltammograms of the positive electrodes in mild aqueous electrolytes at $50 \mathrm{mV} \mathrm{s}^{-1}$. 1: Activated carbon in $1.0 \mathrm{M} \mathrm{LiCl} ; 2: \mathrm{MnO}_{2}, 3$ : $\mathrm{RuO}_{2} \cdot 0.5 \mathrm{H}_{2} \mathrm{O}, 4: \mathrm{RuO}_{2}$ nanosheets in $1.0 \mathrm{M} \mathrm{Li}_{2} \mathrm{SO}_{4}$.

By selecting a positive electrode material with a higher overpotential for oxygen evolution, the cell voltage can be increased. ${ }_{80}$ As shown in the cyclic voltammogram of $\mathrm{MnO}_{2}$ in $1 \mathrm{M} \mathrm{Li}_{2} \mathrm{SO}_{4}$ (Fig. 2), the operating window is shifted to positive potentials, i.e. 0.6-1.6 V vs RHE. Charge/discharge curves of the hybrid EC (Li | PEO-LiTFSI | LTAP | $1.0 \quad \mathrm{M} \mathrm{Li}_{2} \mathrm{SO}_{4}$ aq. $\mid \mathrm{MnO}_{2}$ ) shows 
capacitive behavior between 3.3-4.3 V (Fig. 3(b)). The specific charge calculated from the discharge curve at $0.255 \mathrm{~mA} \mathrm{~cm}^{-2}$ was $31.4 \mathrm{mAh} \mathrm{g}^{-1}$ based on $\mathrm{MnO}_{2}$, which translates to specific energy of $114 \mathrm{Wh} \mathrm{kg}^{-1}$. The $4.3-\mathrm{V}$ cell voltage is higher than any other ${ }_{5}$ EC device, such as EDLCs operating in non-aqueous electrolytes $(2.5 \mathrm{~V})$, with ionic liquids $(3.5 \mathrm{~V})$, or for LICs $(3.8 \mathrm{~V})$.

Another advantage of the advanced hybrid EC is that the use of aqueous electrolytes allows one to fully acknowledge the performance of high capacitance pseudocapacitve materials, for 10 example nanostructured $\mathrm{RuO}_{2}$. As a typical example, hydrous ruthenium oxide $\left(\mathrm{RuO}_{2} \cdot 0.5 \mathrm{H}_{2} \mathrm{O}\right)$ was chosen as the positive electrode. The single electrode capacitance of $\mathrm{RuO}_{2} \cdot 0.5 \mathrm{H}_{2} \mathrm{O}$ in 1 $\mathrm{M} \mathrm{Li}_{2} \mathrm{SO}_{4}$ was $290 \mathrm{~F} \mathrm{~g}^{-1}$ at $5 \mathrm{mV} \mathrm{s}^{-1}$ (Fig. 2), which is lower than the specific capacitance in sulfuric acid but still a few times 15 higher than AC. Thus, a hybrid EC with $\mathrm{RuO}_{2} \cdot 0.5 \mathrm{H}_{2} \mathrm{O}(\mathrm{Li} \mid \mathrm{PEO}-$

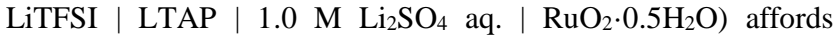
specific capacity of $48.2 \mathrm{mAh} \mathrm{g}^{-1}$ and specific energy of $149 \mathrm{Wh}$ $\mathrm{kg}^{-1}$ at $0.255 \mathrm{~mA} \mathrm{~cm}^{-2}$ (Fig. 3(c)). By using a slightly more exotic material, i.e. $\mathrm{RuO}_{2}$ nanosheets derived from chemical exfoliation 20 of layered $\mathrm{Na}_{0.2} \mathrm{RuO}_{2} \cdot 0.5 \mathrm{H}_{2} \mathrm{O},{ }^{22}$ the capacitance could be enhanced to $543 \mathrm{~F} \mathrm{~g}^{-1}$ at $5 \mathrm{mV} \mathrm{s}^{-1}$ (Fig. 2). A cell voltage of $3.8 \mathrm{~V}$ with specific charge and specific energy of $177 \mathrm{mAh} \mathrm{g}^{-1}$ and 544 $\mathrm{Wh} \mathrm{kg}^{-1}$, respectively, could be realized in a two-electrode configuration (Li | PEO-LiTFSI | LTAP | $1.0 \mathrm{M} \mathrm{Li}_{2} \mathrm{SO}_{4}$ aq.| ${ }_{25} \mathrm{RuO}_{2 \mathrm{~ns}}$ ) at $0.255 \mathrm{~mA} \mathrm{~cm}^{-2}$ (Fig. 3(d)).

For a positive electrode with $177 \mathrm{mAh} \mathrm{g}^{-1}, 45.8 \mathrm{mg}$ of $\mathrm{Li}$ is oxidized/reduced during charge/discharge. Thus hypothetically, the specific charge and specific energy including both electrodes would be $169 \mathrm{mAh} \mathrm{g}^{-1}$ and $520 \mathrm{Wh} \mathrm{kg}^{-1}$, respectively. If it is 30 estimated that the mass of the electrodes would constitute $20 \%$ of a packaged cell, then the anticipated maximum energy density of this cell would be $104 \mathrm{Wh} \mathrm{kg}^{-1}$. The projected energy density is an order higher than state-of-the-art LICs and is in the higher range of rechargeable batteries. Naturally, the use of an expensive, 35 precious material such as ruthenium oxide will be unrealistic for large-scale commercial application. It is noted that thicker $\mathrm{RuO}_{2}$ ns electrodes should afford the same maximum energy density. Nonetheless, the numbers obtained in this study should represent the reachable potential of a $4-\mathrm{V}$ aqueous hybrid EC.

40 In summary, a new aqueous electrochemical capacitor in an asymmetric configuration with high voltage and energy has been demonstrated. A number of advantages of this novel charge storage technology compared to present systems based on capacitive charge storage can be designated. First, the potential 45 window can exceed that of aqueous $\mathrm{MnO}_{2} /$ carbon hybrid ECs, carbon/carbon EDLCs and even LICs by choosing a positive electrode material with high over-potential for the oxygen evolution reaction. Second, the aqueous electrolytes are not only environmentally benign, but also allow the use of a ${ }_{50}$ pseudocapacitve positive electrode with high capacitance such as nanostructured ruthenium oxide. The work is still in its preliminary stage and much research is needed before the present aqueous hybrid ECs can be realized as a potential charge storage device capable of replacing LiBs. The multi-layered Li negative 55 electrode used is far from optimized for capacitor application; massive and impractical amount of lithium is used in the present study due to handling reasons. There is a large family of anode material that could be possibly used, for example the use of Li- doped carbon used in LICs should decrease the overall cell size 60 and weight. Also, development of solid electrolytes capable of use in acidic environments would allow positive electrodes with even higher capacitance. Nonetheless, the proof-of-concept of the advanced hybrid EC using a combination of aqueous capacitor positive electrode in combination with non-aqueous battery 65 negative electrode not only closes the gap between electrochemical capacitors and batteries, but opens the possibility of the use of pseudo-capacitive materials for post-lithium ion battery technology.

70
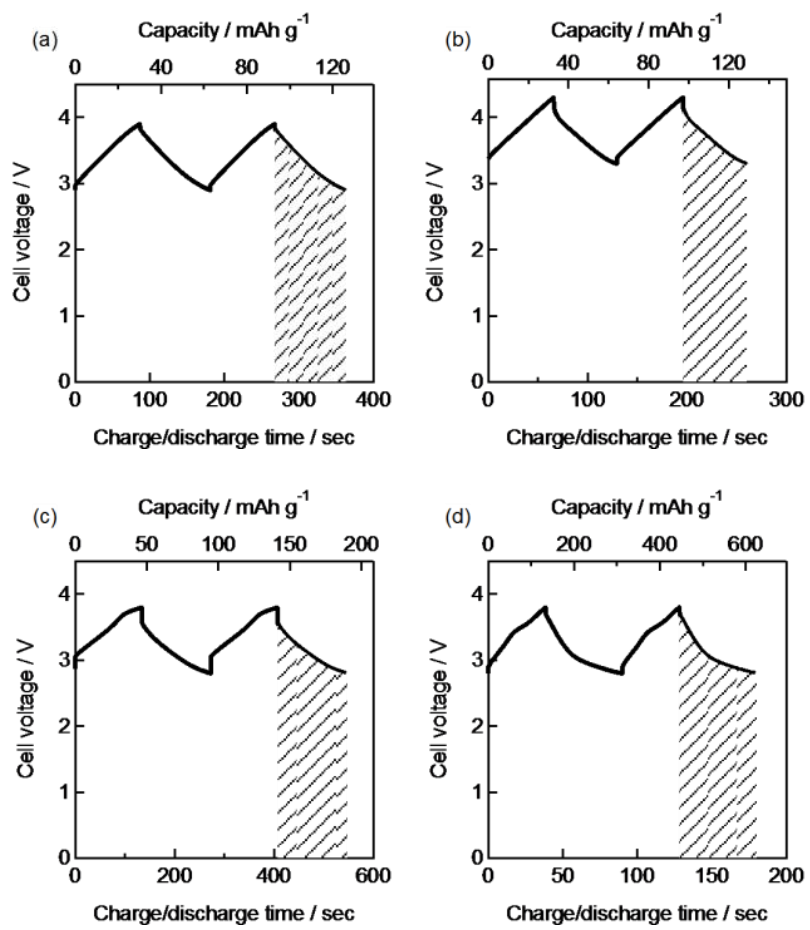

Fig. 3 (a) Steady-state charge/discharge curves of the aqueous hybrid electrochemical capacitor with activated carbon positive electrode and multi-layered Li negative electrode in mild aqueous electrolyte ( $\mathrm{Li} \mid \mathrm{PEO}$ $\left.75 \mathrm{LiTFSI}|\mathrm{LTAP}| 1.0 \mathrm{M} \mathrm{LiCl}\left(60^{\circ} \mathrm{C}\right) \mid \mathrm{AC}\right)$ at $0.255 \mathrm{~mA} \mathrm{~cm}^{-2}$. Steady-state charge/discharge curves of the aqueous hybrid electrochemical capacitor with (b) $\mathrm{MnO}_{2}$, (c) $\mathrm{RuO}_{2} \cdot 0.5 \mathrm{H}_{2} \mathrm{O}$, (d) $\mathrm{RuO}_{2}$ nanosheets as positive electrode materials and multi-layered $\mathrm{Li}$ negative electrode in mild aqueous electrolyte (Li | PEO-LiTFSI | LTAP | $1.0 \mathrm{M} \mathrm{Li}_{2} \mathrm{SO}_{4}\left(60^{\circ} \mathrm{C}\right) \mid$ 80 positive electrode) at $0.255 \mathrm{~mA} \mathrm{~cm}^{-2}$

\section{Acknowledgements}

We gratefully acknowledge support for this work under the Advanced Low Carbon Technology Research and Development Program (ALCA) of the Japan Science and Technology Agency 85 (JST).

\section{Reference}

1. B. Conway, Electrochemical supercapacitors: scientific fundamentals and technological applications, Kluwer Academic/Plenum Publishers, New York, USA, 1999. 
2. P. Simon and Y. Gogotsi, Nature Mater., 2008, 7, 845-854.

3. J. W. Long, D. Bélanger, T. Brousse, W. Sugimoto, M. B. Sassin, and O. Crosnier, MRS Bulletin, 2011, 36, 513-522.

4. G. G. Amatucci, F. Badway, A. Du Pasquier, and T. Zheng, $J$. 5 Electrochem. Soc., 2001, 148, A930-A939.

5. A. Yoshino, T. Tsubata, M. Shimoyamada, H. Satake, Y. Okano, S. Mori, and S. Yata, J. Electrochem. Soc., 2004, 151, A2180-A2182.

6. T. Aida, K. Yamada, and M. Morita, Electrochem. Solid-State 10 Lett., 2006, 9, A534-A536.

7. S. R. Sivakkumar and A. G. Pandolfo, Electrochim. Acta, 2012 65, 280-287.

8. A. S. Aricò, P. Bruce, B. Scrosati, J. Tarascon, and W. van Schalkwijk, Nat. Mater., 2005, 4, 366-377.

$159 . \quad$ T. Brezesinski, J. Wang, S. H. Tolbert, and B. Dunn, Nat. Mater., 2010, 9, 146-151.

10. X. Lang, A. Hirata, T. Fujita, and M. Chen, Nat. Nanotechnol., 2011, 6, 232-236.

11. K. Naoi and P. Simon, Interface, 2008, 17, 34-37.

G. Wang, L. Zhang, and J. Zhang, Chem. Soc. Rev., 2012, 41, 797-828.

13. D. A. McKeown, P. L. Hagans, L. P. L. Carette, A. E. Russell, K. E. Swider, and D. R. Rolison, J. Phys. Chem. B, 1999, 103, 4825-4832.

2514 W. Sugimoto, H. Iwata, Y. Yasunaga, Y. Murakami, and Y. Takasu, Angew. Chem. Int. Ed. Engl., 2003, 42, 4092-4096.

15. W. Sugimoto, H. Iwata, K. Yokoshima, Y. Murakami, and Y. Takasu, J. Phys. Chem. B, 2005, 109, 7330-7338.

16. W. Sugimoto, K. Yokoshima, Y. Murakami, and Y. Takasu,

30 W. Sugimoto, K. Yokoshima, Y. Muraka
Electrochim. Acta, 2006, 52, 1742-1748.

17. J. P. Zheng, P. J. Cygan, and T. R. Jow, J. Electrochem. Soc., 1995, 142, 2699-2703.

18. T. Brousse, M. Toupin, and D. Bélanger, J. Electrochem. Soc., 2004, 151, A614-A622.

35 19. T. Zhang, N. Imanishi, Y. Shimonishi, A. Hirano, J. Xie, Y. Takeda, O. Yamamoto, and N. Sammes, J. Electrochem. Soc., 2010, 157, A214-A218.

20. T. Zhang, N. Imanishi, Y. Shimonishi, A. Hirano, Y. Takeda, O. Yamamoto, and N. Sammes, Chem. Commun., 2010, 46, 16611663.

21. J. W. Long, K. E. Swider-Lyons, R. M. Stroud, and D. R. Rolison, Electrochem. Solid-State Lett., 1999, 3, 453-456.
22. K. Fukuda, T. Saida, J. Sato, M. Yonezawa, Y. Takasu, and W. Sugimoto, Inorg. Chem., 2010, 49, 4391-4393.

\section{${ }_{45}$ Notes}

${ }^{a}$ Materials and Chemical Engineering, Faculty of Textile Science and Technology, Shinshu University, 3-15-1 Tokida, Ueda, Nagano, 386-8567, Japan. Fax: +81-268-21-5452; Tel: +81-268-21-5455; E-mail: wsugi@shinshu-u.ac.jp

$50{ }^{b}$ Department of Chemistry, Faculty of Engineering, Mie University, 1577 Kurimamachiya-cho, Tsu, Mie, 514-8507, Japan. Fax: +81-59-231-9478; Tel: +81-59-231-9420; E-mail: imanishi@chem.mie-u.ac.jp 